\title{
COMPETÊNCIA EM INFORMAÇÃO: PERSPECTIVA DIDÁTICA PEDAGÓGICA
}

\author{
INFORMATION LITERACY: PERSPECTIVE \\ EDUCATIONAL TEACHING
}

\author{
Gabriela Belmont de Farias* \\ Regina Célia Baptista Belluzzo**
}

\begin{abstract}
RESUMO:
Introdução: Apresenta reflexão sobre as ações de ensino aprendizagem que podem influenciar positivamente na formação dos discentes do curso de Biblioteconomia no contexto brasileiro, ao apropriar-se da "Modelagem Pedagógica de Desenvolvimento da Competência em Informação", colocando-a em prática por meio de intervenções pedagógicas. Objetivo: O objetivo foi elaborar o modelo supracitado tendo como base a normativa da The Association of College and Research Libraries que consideram que a competência em informação é comum a todas as disciplinas, a todos os contextos de aprendizagem e a todos os níveis de ensino. Metodologia: A pesquisa configura-se por uma abordagem qualitativa de natureza bibliográfica e exploratória.

Resultados: Modelagem conceitual pedagógica de desenvolvimento da Colnfo para os curso de graduação. Conclusões: Trata-se de uma contribuição de aspecto inovador e social aos interessados na adoção de novas posturas nesta ambiência de ensino-aprendizagem, além de auxiliar na compreensão das questões fundamentais relacionadas à competência em informação, possibilitando a sua apropriação junto aos cursos de Biblioteconomia e promovendo o aprofundamento das reflexões ora apontadas e a necessidade de implementá-la como parte da formação básica do bibliotecário.
\end{abstract}

Palavras-chave: Competência em Informação. Formação Profissional. Biblioteconomia. Ensino.

\section{INTRODUÇÃO}

A explosão informacional, juntamente com as tecnologias de informação e comunicação (TIC), somada a demanda por profissionais mais produtivos, criativos e competentes, conduz uma reflexão sobre o desenvolvimento da

* Doutora em Ciência da Informação. E-mail: gabibfarias@gmail.com

** Doutora em Ciência da Comunicação. Professora do Programa de Pós-graduação em Ciência da Informação (UNESP) E-mail: rbelluzzo@gmail.com 
competência em informação no meio universitário, levando em consideração o fato de que é "[...] um processo de aprendizagem, compreendida como ação contínua e prolongada, que ocorre ao longo da vida." (GASQUE, 2012, p.39). A formação profissional de qualidade é um pré-requisito para a inserção da pessoa na sociedade do conhecimento. Para tanto, é necessário se refletir sobre novos modelos educacionais, pois "o ensino tradicional, em que os aprendizes decoram os conteúdos sem compreendê-los e no qual o professor é o detentor do saber e responsável por transmitir conhecimentos, entra em crise." (GASQUE, 2012, p.25).

Com procedência nas revoluções sociais do século XX e com as lutas sociais e políticas desencadeadas em decorrência da ditadura militar, a educação e a cultura passaram a ser concebidas como constitutivas da cidadania e, portanto, como direitos dos cidadãos. A universidade é instituição social, isto é, uma ação social, uma prática social fundada no reconhecimento público de sua legitimidade e de suas atribuições, num princípio de diferenciação, que the confere autonomia perante outras instituições sociais, e estruturadas por ordenamentos, regras, normas e valores de reconhecimento e legitimidade internos a ela. (CHAUI, 2003).

O ensino superior tem como primícias para seu funcionamento o tripé do ensino-pesquisa-extensão, tendo um papel fundamental para a sociedade, pois reúne "[...] um conjunto de funções associadas ao progresso e a transmissão do saber: pesquisa, inovação, ensino e formação, educação permanente". (DELORS, 1998, p.141). Deve considerar as variadas condições de desenvolvimento e inovação da atual sociedade complexa, migrando de uma profissão tradicional de transmissora de informação e de cultura para um comportamento de ensinar a aprender e a pensar, preparando pessoas capazes de aplicar os conhecimentos, facilitando o uso da inteligência na vida profissional e no cotidiano social. (BELLUZZO, 2007).

A missão do ensino superior para o século $X X I$, segundo a Declaração Mundial sobre o Ensino Superior da Organização das Nações Unidas para a Educação, a Ciência e a Cultura (UNESCO), abrange os seguintes aspectos: 
a)formar profissionais altamente qualificados e cidadãos responsáveis, capazes de atender às necessidades de todos os aspectos da atividade humana; b) constituir um espaço aberto que propicie a aprendizagem permanente; c) promover, gerar e difundir conhecimentos por meio da investigação e proporcionar as competências técnicas adequadas para o desenvolvimento cultural, social e econômico das sociedades; d) compreender, interpretar, preservar, reforçar, fomentar e difundir as culturas nacionais e regionais, internacionais e históricas, em um contexto de pluralismo e diversidade cultural; e) consolidar os valores da sociedade, mostrar aos jovens o valor da cidadania e proporcionar perspectivas críticas e objetivas, a fim de propiciar o debate sobre as opções estratégicas e o fortalecimento de enfoques humanistas. (UNESCO, 1998).

Se o ensino superior tem a função de formar pessoas críticas e reflexivas, e que contribuam para o desenvolvimento econômico e social, a competência em informação se faz elemento indissociável do ensino, pois permitirá ao aluno o desenvolvimento de habilidades críticas, criativas e reflexivas. Takahashi (2000, p.45) corrobora e amplia essa concepção, ao acentuar que a função do ensino superior é [...] muito mais que treinar pessoas para o uso de tecnologias de informação e comunicação: trata-se de investir na criação de competências suficientemente amplas que lhes permitam ter uma atuação efetiva na produção de bens e serviços, tomar decisões fundamentadas no conhecimento, operar com fluência os novos meios e ferramentas em seu trabalho, bem como aplicar criativamente as novas mídias, seja em usos simples e rotineiros, seja em aplicações mais sofisticadas. Tratase também de formar indivíduos para 'aprender a aprender', de modo a serem capazes de lidar positivamente com a contínua e acelerada transformação da base tecnológica.

O objetivo deste artigo é apresentar a proposta de modelagem pedagógica de desenvolvimento da competência em informação aplicável aos cursos de Biblioteconomia, além de discutir a necessidade de sensibilização quanto à inserção da filosofia da competência em informação no ensino superior, de planejar atividades de orientação para a aquisição dessa competência. No entendimento de Jesus Lau (2007, p.4) "as habilidades em informação são fatores chave na aprendizagem ao longo da vida e o primeiro passo na consecução das metas educacionais de qualquer aprendiz". O recorte 
neste artigo tem foco no ensino de Biblioteconomia, pois, segundo as Diretrizes Curriculares (BRASIL, 2001), os cursos dessa área do conhecimento têm a missão de formar bibliotecários competentes, proficientes e criativos para solucionar as demandas de sua prática profissional, o que não significa, porém, que as noções aqui estabelecidas não possam ser redirecionadas para outra área do conhecimento.

\section{COMPETÊNCIA EM INFORMAÇÃO}

O entendimento de competência em informação (Colnfo), a priori estava associado em torno do papel educacional das bibliotecas e da necessidade de efetivar programas educacionais com esse foco, além de priorizar o acesso e busca da informação em meios tecnológicos. Já na década de 1990, o conceito da American Library Association (ALA) é aceito por toda a comunidade (bibliotecários e pesquisadores da área), surgindo, assim, outras perspectivas de fundamentação teórica e metodológica sobre a temática.

As diretrizes da Colnfo elaboradas por Doyle (1994) constituíram instrumento que buscou definir um conjunto de habilidades que norteassem 0 ensino médio. A articulação entre conhecimento busca, acesso, organização e uso da informação na resolução de problemas é parte integrante das habilidades a serem desenvolvidas durante a formação básica da pessoa. Nesse mesmo período, Bruce (2000) inseriu, no campo de estudo da Colnfo, o modelo relacional, em que ela pressupõe que o desenvolvimento dessa competência é concebido mediante as experiências vividas pelo próprio sujeito. Outro elemento histórico conceitual é a definição estabelecida pela The Association of College and Research Libraries (ACRL), que estabelece a Colnfo como sendo um conjunto de habilidades requeridas das pessoas para reconhecer quando a informação é necessária e possuir habilidade para localizar, avaliar, e usar com efetividade a informação recuperada (ACRL, 2000). Esses conceitos constituem base para inúmeras atividades, de âmbito internacional e nacional, desenvolvidas em prol do fortalecimento e desenvolvimento da Colnfo. 
Na perspectiva de Campello (2003), o documento que concretiza a assimilação do conceito Colnfo pela classe biblioteconômica é o Information Power. Este documento expressa um conjunto de recomendações para o desenvolvimento da Colnfo, nas quais as habilidades estão agrupadas em três grupos: a) competência para lidar com informação-relacionada ao acesso à informação de forma eficiente e efetiva, avalia a informação de forma crítica e competente e a usa com precisão e criatividade; b) informação para aprendizagem independente- vinculada à busca persistente da informação relacionada aos interesses pessoais, aprecia diversas formas criativas se exprimir da informação e se esforça para obter excelência na busca da informação para produção de conhecimento; e c) informação para responsabilidade social- relacionada a reconhecer a importância da informação para a sociedade democrática, tem comportamento ético no que concerne à informação e à tecnologia da informação, e participa efetivamente de grupos, a fim de buscar e gerar informação. (ALA, 1998).

Não se pode deixar de citar os modelos de desenvolvimento da Colnfo e os padrões e indicadores de performance que são até hoje parâmetros para muitos países.

Quadro 1 - Modelos e padrões de competência em informação.

\begin{tabular}{|c|c|c|}
\hline MODELOS & AUTORES & PAIS DE ORIGEM \\
\hline $\begin{array}{l}\text { Taxonomies of the School Library } \\
\text { Media Program. } \\
\text { The Organized Investigator - Circular } \\
\text { Model }\end{array}$ & David Loertscher & \multirow{5}{*}{$\begin{array}{l}\text { ESTADOS } \\
\text { UNIDOS }\end{array}$} \\
\hline $\begin{array}{l}\text { The Big6 Skills Information Problem- } \\
\text { Solving Approach to Information } \\
\text { Skills Instruction }\end{array}$ & $\begin{array}{l}\text { Michael Eisenberg } \mathrm{e} \\
\text { Robert Berkowitz }\end{array}$ & \\
\hline $\begin{array}{l}\text { Pathways to Knowledge Follett's } \\
\text { Information Skills Models }\end{array}$ & $\begin{array}{l}\text { Marjorie Pappas e Ann } \\
\text { Tepe }\end{array}$ & \\
\hline The Research Cycle & Jamie Mackenzie & \\
\hline $\begin{array}{l}\text { Information Literacy: Dan's Generic } \\
\text { Model }\end{array}$ & Dan Barron & \\
\hline INFOZONE & $\begin{array}{l}\text { Assiniboine } \\
\text { School Douth } \\
\text { Winnipeg }\end{array}$ & CANADÁ \\
\hline $\begin{array}{l}\text { PADRÕES UNIVERSITÁRIOS } \\
\text { INFORMAÇÃO }\end{array}$ & COMPETÊNCIA EM & PAIS DE ORIGEM \\
\hline Information Literacy Competency St & rds of $H$ & ESTADOS \\
\hline
\end{tabular}




\begin{tabular}{|l|c|}
\hline da (ACRL/ALA). & UNIDOS \\
\hline SCONUL'S the Seven Pillars of information Literacy. & INGLATERRA \\
\hline $\begin{array}{l}\text { Information Literacy Standards - Council of Australian University } \\
\text { Librarians (CUAL). }\end{array}$ & AUSTRALIA \\
\hline $\begin{array}{l}\text { Australian and New Zealand Information Literacy Framework - } \\
\text { Institute for Information Literacy (ANZIIL). }\end{array}$ & AUSTRALIA E \\
NOVA ZELÂNDIA \\
\hline
\end{tabular}

Fonte: Farias, 2014.

Os modelos e padrões podem ser usados como instrumentos orientadores para o desenvolvimento de atividades e programas de Colnfo, pois são "parâmetros norteadores para uma prática que sustente um objetivo concreto." (SANTOS, 2013, p.30). A fim de ajudar no entendimento e na elaboração de uma consciência pública da Colnfo, com vistas a solucionar os problemas relacionados à "explosão informacional", modelos elaborados por bibliotecários e educadores surgem para o desenvolvimento das habilidades requeridas, na maioria direcionada às escolas e universidades. Assim, pode-se dizer que os modelos representam de maneira simplificada e funcional aspectos fundamentais de um processo, com vistas a uma melhor interpretação deste ou à previsão de sua evolução, tomando como base as certas variáveis observadas experimentalmente (PIANTOLA; VITORINO, 2011).

Quanto aos padrões, podem ser considerados como um conjunto de dimensões, concepções ou variáveis aprovadas por um organismo reconhecido que provê, pelo uso comum e repetitivo, regras, diretrizes ou características de produtos, processos ou serviços, cuja obediência não é obrigatória; ou, ainda, um conceito, norma, princípio estabelecido por acordo, por uma autoridade, costume, e geralmente usado como um exemplo modelo para comparar medir a qualidade o desempenho de uma prática ou procedimento. Por sua vez, os indicadores correspondem às variáveis mensuráveis usadas como representação de um padrão ou fator de quantidade.

Destaca-se a existência de padrões denominados Information Literacy Competency Standards of Higher Education- ACRL (2000) compostos por cinco padrões e 22 indicadores de desempenho voltados aos ambientes de ensino superior, os quais foram desenvolvidos pela ACRL para oferecer subsídio a formação de pessoas capazes de enfrentar a diversidade informacional dentro de vários ambientes, seja de trabalho, educacional ou na vida pessoal. 
Com base nos elementos aqui apresentados, será adotada a definição de Belluzzo (2005b), por se considerar que atende às expectativas adotadas, a saber:

A competência em informação constitui-se em processo contínuo de interação e internalização de fundamentos conceituais, atitudinais e de habilidades específicas como referenciais à compreensão da informação e de sua abrangência, em busca da fluência e das capacidades necessárias à geração do conhecimento novo e sua aplicabilidade ao cotidiano das pessoas e das comunidades ao longo da vida. (BELLUZZO, 2005b, p.38).

Fica evidente, nesta definição, a necessidade de a pessoa de aprender a produzir um conhecimento desde o procedimento que se inicia na busca, permeia o acesso e termina no uso eficiente da informação, seja aplicada a uma necessidade específica, na resolução de problemas, na tomada de decisão, seja buscando o aprendizado contínuo, desenvolvendo competências que objetivem conhecer e usufruir do complexo ambiente informacional.

A adaptação e a socialização dos indivíduos na sociedade só se tornam efetivos quando o mesmo possui a capacidade de:

Determinar a extensão das informações necessárias; acessar a informação de forma efetiva e eficientemente; avaliar criticamente a informação e suas fontes; incorporar a nova informação ao conhecimento prévio; usar a informação de forma efetiva para atingir objetivos específicos; compreender os aspectos econômico, legal e social do uso da informação, bem como acessá-la e usá-la ética e legalmente. (GASQUE, 2012, p. 31-32).

Observa-se que aquele capaz de atender a demanda dessa sociedade complexa necessita compreender a informação desejada no contexto no qual está inserido, para que na sua busca haja um pensamento crítico, a fim de poder avaliar, selecionar e incorporar fontes de informações que venham a atender, especificamente, as necessidades expressas e que, ao fazer o uso da informação, é primordial que compreenda os aspectos econômicos, legais e sociais, bem como a forma ética de uso desta informação, tendo como fim a resolução de problemas e a realização de atividades específicas e circunscritas, visando atingir diretrizes que possam ser norteadoras de uma sociedade sustentável. 
Na compreensão de Belluzzo (2013), para que se possa estabelecer a competência em informação sustentável, é necessário compreender três requisitos fundamentais: competência em informação para a cidadania reporta-se ao uso crítico de dados e informação; competência em informação para o crescimento econômico - refere-se ao uso criativo e intensivo do conhecimento e à combinação eficiente dos serviços de informação; e competência em informação para a empregabilidade, relacionada ao desenvolvimento contínuo da pessoa com estratégias necessárias para o acesso e o êxito econômico. Belluzzo (2013) alerta para reflexão dos requisitos principais para o desenvolvimento da competência em informação no contexto brasileiro: Existência de espaços de intercâmbio e participação por meio do fomento de práticas pedagógicas e informacionais, tendo como base a filosofia da educação para todos.

\begin{abstract}
Estabelecimento de estreita relação entre as bibliotecas e as escolas, mediante trabalho integrado e conjunto, com o intuito de promover a leitura e a pesquisa. Garantia do acesso e uso da informação de forma inteligente para a geração de conhecimento às comunidades assistidas e populações vulneráveis. Atualização de princípios e práticas de condutas de gestão da informação àqueles que atuam como mediadores e multiplicadores no desenvolvimento da Competência em Informação, contribuindo com a inovação e o desenvolvimento social. (BELLUZZO, 2013, p.77).
\end{abstract}

A autora ressalta, ainda, algumas situações desafiantes às experiências e ao desenvolvimento da Colnfo. Desconhecimento sobre as questões que envolvem a Colnfo e sua relação com os pilares da educação para o século XXI e o direito universal de acesso à informação, presentes em Manifestos da UNESCO e em políticas públicas nacionais e mundiais. Necessidade de sensibilização dos gestores públicos e de instituições privadas para a importância do desenvolvimento da Colnfo como parte integrante de uma ambiência de expressão e construção individual e coletiva e sua relação com o exercício da cidadania e com o aprendizado ao longo da vida. 
Criação e implantação de Programas de Desenvolvimento da Competência em Informação, apoiados na formação de Comunidades de Aprendizagem, que possam estar atuando com efetividade na utilização de modelos de educação tradicionais e inovadores a fim de contribuir com a inclusão social no Brasil. (BELLUZZO, 2013, p.78).

A complexidade de estabelecer uma conexão da filosofia da competência em informação e os ambientes educacionais e corporativos é desafiadora, pois a compreensão dessa filosofia, muitas vezes, é limitada, prejudicando o desenvolvimento de programas educacionais ou de capacitação. Nesse sentido, destaca-se uma das contribuições de Uribe-Tirado (2010), que em suas pesquisas, categorizou as bibliotecas nas universidades brasileiras conforme os graus de incorporação da filosofia Compinfo/ALFIN, mediante o uso de indicadores que podem ser também utilizados pelos cursos de Biblioteconomia como parâmetros de análise. Essas categorizações estão divididas em quatro níveis, conforme se representa no Quadro2.

Quadro 2 - Indicadores da situação das bibliotecas universitárias em relação ao desenvolvimento de programas de competência em informação.

\begin{tabular}{|c|c|}
\hline COMPROMETIDAS & \\
\hline $\begin{array}{l}\text { Cursos oferecidos para o } \\
\text { desenvolvimento da competência em } \\
\text { informação: instrumental } \\
\text { aprendizagem ao longo da vida+ } \\
\text { pensamento crítico; } \\
\text { cursos/módulos específicos e imersos } \\
\text { oficialmente nos currículos dos cursos } \\
\text { acadêmicos. A competência em } \\
\text { informação é desenvolvida de forma } \\
\text { transversal e como disciplina }\end{array}$ & $\begin{array}{l}\text { Cursos oferecidos para } \\
\text { desenvolvimento da competência em } \\
\text { informação: instrumental t } \\
\text { aprendizagem ao longo da vida+ } \\
\text { pensamento crítico. }\end{array}$ \\
\hline \multicolumn{2}{|l|}{ INICIANDO } \\
\hline $\begin{array}{l}\text { Formação de usuários. Capacitação } \\
\text { para o uso da biblioteca e dos serviços } \\
\text { gerais. Alguns cursos de ordem } \\
\text { instrumental para recuperação de } \\
\text { informaçâo: utilizando catálogo/bases } \\
\text { de dados. Começando a abordar a } \\
\text { necessidade de mudança de uma } \\
\text { formação tradicional para trabalhar } \\
\text { as demais competências }\end{array}$ & $\begin{array}{l}\text { DESCONHECEDORAS } \\
\text { Formação de usuários. Capacitação } \\
\text { para o uso de catálogo/bases de } \\
\text { dados. Não há presença de um } \\
\text { programa de desenvolvimento de } \\
\text { competência em informação. }\end{array}$ \\
\hline
\end{tabular}

Fonte: Adaptado de Uribe-Tirado (2011).

Para Coonan (2011), a competência em informação parece ser um elemento fundamental da prática universitária, pois ela se manifesta na compreensão específica da criação de conhecimento, a atividade acadêmica, e 
processos de ensino-aprendizagem das disciplinas. O meio acadêmico, entretanto, ao mesmo tempo em que se mostra favorável à ideia de aumentar as habilidades relacionadas à Colnfo dos alunos, reluta em incorporar a filosofia na grade curricular, em especial, dos cursos de Biblioteconomia. Se, houver, a informação de alto nível de manipulação é crucial para a missão acadêmica, e se a Colnfo é fundamental para a aprendizagem em todos os contextos, por que não inseri-la como um elemento significativo no currículo acadêmico?

Anteriormente, Stubbings e Franklin (2006) já indicavam haver uma série de razões para que a filosofia da competência em informação não estivesse inserida nos currículos acadêmicos: a falta de compreensão da filosofia da competência em informação por parte dos professores, a confusão com o conceito da Colnfo com competência em tecnologia da informação - (TI) e os equívocos dos estudantes que se acreditam competentes em informação por saberem pesquisar na Internet.

Badke (2010) vai mais longe, ao acentuar que a Colnfo é um elemento "invisível" dentro da universidade, por uma série de causas: Porque ela é mal compreendida, os gestores acadêmicos não a inserem nas agendas das suas instituições, o embasamento teórico da literatura sobre a competência em informação permanece exclusivamente com os bibliotecários, há uma falsa crença de que a Colnfo é adquirida apenas pela experiência, há uma falsa suposição de que a capacidade tecnológica é o mesmo que Colnfo, a cultura do corpo docente faz com que a competência em informação seja menos importante do que as outras atividades de educação, professores têm uma percepção limitada da competência em informação e os organismos de acreditação não tem ainda informações avançadas sobre a Colnfo para uma posição viável no ensino superior. (BADKE, 2010, p.129).

Observa-se a falta de entendimento no contexto universitário sobre a Colnfo, que pode ser atribuída, segundo Coonan (2011), a um conflito de percepção em torno da natureza da informação e como lidar com isso. Este conflito levou a uma separação dos aspectos funcionais e intelectuais do termo "informação"; e, nesse conflito conceitual, a competência em informação se fez 
reducionista e alinhada com habilidades de nível operacional e relacionada às atividades funcionais ou básicas.

Separar os aspectos funcionais de lidar com a informação em seu contexto e práticas disciplinares pode suscitar uma não contextualização da filosofia da competência em informação, o que pode ser visto como complementar as práticas acadêmicas, em vez de uma parte determinante da missão acadêmica. Levando a filosofia da competência em informação como área de apoio, desta forma, poderá alcançar um grau de notoriedade e visibilidade, atraindo apoio institucional e recursos; no entanto, isso também suscita uma percepção da Colnfo como opcional ou complementar, em vez de um elemento fundamental da teoria e da prática universitária. No ensino superior, a competência em informação não é um tema secundário, mas todo um modo de pensar sobre a informação e seu uso.

A filosofia da competência em informação é tão complexa, sofisticada e entrelaçada com a forma como se usa a informação - todos os dias, bem como academicamente - que se devem demandar esforços para percebê-la:

como indivisível dos processos que constituem a pesquisa em seu contexto mais amplo: os processos de avaliação, comparação e seleção; de questionamento e problema de enquadramento; de sintetizar visualizações variante e criar novos. Assim, há uma necessidade imperiosa de reabilitar a percepção da competência em informação e reconhecer que não é apenas um conjunto de habilidades e competências, mas um contínuo que começa com habilidades e competências e sobe em direção de alto nível de comportamentos e abordagens intelectuais e metacognitivas. (COONAN, 2011, p.20).

A fim de estabelecer verdadeiramente uma abordagem da filosofia da competência em informação que apoia os alunos em cada etapa da graduação, é necessária maior conscientização e impõe-se mais reflexão sobre os métodos de ensino, estilos e práticas por parte dos professores; mas há uma necessidade paralela de apoio institucional para os membros da equipe educacional (professores, bibliotecários) que vai aplicar a filosofia da competência em informação no ensino como um continuam de aprendizagem e desenvolvimento. 
A perspectiva de integração da Colnfo ao currículo universitário requer uma compreensão, da parte dos gestores, bibliotecários e docentes, de que a competência em informação é "uma estratégia formativa, a ser desenvolvida ao longo do período escolar, como uma competência transversal, sobretudo porque cria as bases para a busca da formação ao longo da vida". (VARELA; BARBOSA; FARIAS, 2013, p.202). Além disso, a Colnfo está estreitamente relacionada com as competências educacionais. A incorporação dela ao ensino universitário:

Aumenta a capacidade de busca efetiva da informação em distintos suportes e formatos informacional;Autonomia na investigação e avaliação de recursos informacional usados para elaboração do trabalho acadêmico; Desenvolve a capacidade de análise em ralação ao excesso de informação; Usa um maior número de recursos de informacional de confiabilidade e relevante;Reduz o plagio nos trabalhos acadêmicos;Melhora a capacidade de organização da informação; eMelhora a capacidade de comunicação oral e escrita. (CUEVAS CERVERÓ, 2012, p.96-97).

Os argumentos e razões ora expostos explicam a necessidade de incorporar a filosofia da competência em informação ao ensino superior. Relativamente à formação biblioteconômica, Mata e Casarin (2012), após realizarem um levantamento nos sites de instituições universitárias brasileiras para identificar a existência de disciplinas de competência em informação e de formação pedagógica na formação do bibliotecário, apontaram que a necessidade da formação, do futuro profissional está pautada nos preceitos da competência em informação e com bases pedagógicas, já que este profissional atuará como coordenador ou educador de programas de desenvolvimento da competência em informação. Elas suscitam a ideia de que a filosofia da competência em informação pode ser inserida como um componente curricular por meio de disciplinas específicas ou já existentes, por meio da pesquisa, ou, ainda, por práticas pedagógicas com os alunos de biblioteconomia. "O ideal seria encontrar uma abordagem da competência em informação em disciplina de educação de usuário." (MATA; CASARIN, 2012, p.12). Não será demais lembrar, entretanto, que a abordagem da Colnfo deve perpassar todas as disciplinas, pois ela é um conteúdo transversal, ou seja, 
Esse viés dá-se pelo fato de que a competência em informação possui caráter transdisciplinar, que perpassa conteúdos formais, mas que busca a interação da pessoa na sociedade por meio de conhecimento de mundo que lhe permite situar-se em seu contexto. (SANTOS, 2013, p. 39).

O princípio do ensino-aprendizagem da competência em informação está relacionado à prática como norteadora pedagógica central, onde estão fundamentadas as ópticas social, cultural e psicológica que possibilitem aos alunos serem independentes e produtivos no âmbito informacional. Nesta concepção, pode-se entender que a finalidade da prática pedagógica é de proporcionar experiências de ação didática e convergir entre a ação pedagógica e a Colnfo.

Ao pensar em ações de ensino-aprendizagem da Colnfo, é preciso partir da constituição de um compromisso no âmbito institucional para que as ações tenham êxito. As ações devem estar pautadas sem concepção globalizada e serem efetivadas por meio de projetos e procedimentos de aprendizagem sistemáticos. A filosofia da competência em informação exige nova concepção de aprendizagem e de atitude pedagógica da parte dos educadores e do próprio projeto pedagógico dos cursos. Gasque (2012) aponta os desafios a serem superados ao implementar a filosofia da competência em informação no ambiente educacional: "Dificuldade em mudar a cultura pedagógica, formação inadequada dos professores, concepção de ensino-aprendizagem, organização do currículo e ausência de infraestrutura adequada de informação". (GASQUE, 2012, p.151-152).

Tais dificuldades conduzem a se refletir sobre o papel das instituições educacionais na sociedade, surgindo questionamentos que envolvem analisar se realmente elas possibilitam um espaço dinâmico no qual as pessoas desenvolvem a capacidade de pensar criticamente, de exprimir autonomia por intermédio da transdicisplinaridade oferecida no currículo e pelas experiências vivenciadas no meio acadêmico. Além desses desafios, outros aspectos devem ser levados em conta, tais como:

Estabelecer uma infraestrutura básica de telecomunicações e redes de computadores, de modo a tornar acessíveis, através da tecnologia, as informações relativas à comunidade 
educacional, bem como garantir o acesso a dados, fatos, contecimentos e conhecimentos que envolvem a comunidade e o mundo. Facilitar a integração da informação ao currículo, criando uma cultura de uso da biblioteca; isto implica necessariamente na valorização da biblioteca enquanto sistema multicultural e pluralístico. Oferecer todas as oportunidades para que a comunidade educacional se aproprie da tecnologia e dos recursos informacionais em seus variados formatos, de modo que se crie um ambiente educacional favorável à pesquisa, à investigação, enquanto processo de busca e uso de informações para a construção de conhecimento e tomadas de decisão conscientes. Fomentar o diálogo entre todos os membros da comunidade educacional.Buscar parcerias, 0 trabalho cooperativo, transdisciplinar, integrado.O bibliotecário deve adquirir uma postura ativa, dialogando com os docentes, buscando novas atividades e práticas pedagógicas que potencializem os processos de aprendizado a partir da busca e uso da informação, a investigação, o pensamento crítico, incentivando o aprendizado independente, auto-orientado dos estudantes. Enquanto espaço, a Biblioteca deve ser o tanto quanto possível um ambiente propício ao estudo, à descoberta, autoexplicativa, proporcionando as condições ideais à investigação e o aprendizado. Os bibliotecários que nela atuam devem incentivar o diálogo interno e externo com a comunidade acadêmica, tornando-a uma organização aprendente. (DUDZIAK, 2002a, p.8-9).

Haja vista, que o desenvolvimento de ações de Colnfo na perspectiva do ensino superior pode ser definido por meio de uma

Política de formação em competência em informação, elaborada por um comitê acadêmico representado por docentes de diferentes áreas, setores estratégicos da administração, estudantes, pesquisadores, bibliotecários, profissionais da área de informática e representante da sociedade, este último poderá contribuir com indicações de necessidades voltadas para o mercado de trabalho. (CAVALCANTE, 2006, p.56).

A política de formação em Colnfo poderá ter como base de sua elaboração o guia de "Diretrizes sobre desenvolvimento de habilidades em informação para a aprendizagem permanente", elaborado por Jesús Lau (2007). Este guia constitui modelo conceitual e informações para estruturar a criação de ações de desenvolvimento de habilidades em informação (DHI). 


\section{METODOLOGIA}

Esta pesquisa é resultado de uma tese, a qual objetiva, com base em teorias fundamentadoras da Colnfo, aprofundar as percepções teórico-práticas do desenvolvimento das habilidade informacionais dos discentes da área de Biblioteconomia, bem como de outros curso de graduação, visando debater e propor estratégias para atuação do docente no processo de ensinoaprendizagem.

A investigação realizada é de natureza documental, exploratória e qualitativa. Foram analisados documentos produzidos por instituições representativas, nacional e internacionalmente.

Foram concretizadas três etapas correlacionadas e integrativas. A primeira teve como foco a revisão da literatura nas áreas da Educação, Psicologia e Ciência da Informação, com intuito de situar e formar um embasamento sólido e argumentativo sobre o desenvolvimento da Colnfo no contexto universitário. A segunda etapa direcionou a análise documental e das representações sociais sobre os documentos do MEC, Declaração Mundial sobre Educação Superior no Século XXI: Visão e Ação - 1998, Declaração de Maceió sobre Competência em Informação e o Manifesto de Florianópolis sobre a Competência em Informação e as Populações Vulneráveis e Minorias, utilizando o método do Discurso do Sujeito Coletivo. A terceira etapa concentrou-se na elaboração de uma Modelagem Pedagógica de Desenvolvimento da Competência em Informação - (MPDColnfo), direcionada ao contexto universitário. Essa modelagem teve como princípio o embasamento teórico feito anteriormente, as análises realizadas nos documentos oficiais e os padrões e indicadores de desempenho de Competência em Informação desenvolvidos por ACRL (2000).

\section{RESULTADOS: APRESENTAÇÃO E DISCUSSÃO DA MODELAGEM CONCEITUAL PEDAGÓGICA DE DESENVOLVIMENTO DA COINFO}

Tendo em vista as reflexões expostas, apresenta-se modelagem conceitual pedagógica para o desenvolvimento da Colnfo - (MPDColnfo), 
ressaltamos que a modelagem foi desenvolvida tendo como base o documento normativo da ACRL que consideram que a Colnfo é comum a todas as disciplinas, a todos os contextos de aprendizagem e a todos os níveis de ensino.

A MPDColnfo permite oferecer subsídios à sua inserção como uma disciplina e/ou um conteúdo transversal nos cursos de graduação em Biblioteconomia. A intenção é oferecer uma modelagem conceitual de intervenção formativa para se pensar em novas condutas de ensinoaprendizagem com base no desenvolvimento de Colnfo.

A concepção da modelagem tem como temática de fundo os cinco padrões e indicadores da Colnfo estabelecidos pela ACRL (2000). Essa escolha se justifica pela integração dessa modelagem com a realidade do contexto brasileiro e por ser um dos mais utilizados no meio acadêmico, além de estimular a formação de pessoas capazes de enfrentar a diversidade informacional dentro de diversos ambientes.

A modelagem aqui oferecida tem caráter orientador e instrumental, na tentativa de contribuir para a elaboração de um documento de natureza didático-pedagógica. A intenção é que, na medida em que haja a sua apropriação pelos docentes que atuam em cursos de Biblioteconomia, seja criada uma comunidade de prática, com o propósito de possibilitar a troca de experiência e disseminação de outras vivências em outras áreas a fim de promover um aprofundamento das reflexões apontadas.

Neste âmbito, buscou-se $\mathrm{o}$ amparo em questionamentos que possibilitassem fornecer respostas ou opções, tais como: Como desenvolver intervenções formativas para o desenvolvimento da competência em informação direcionadas às necessidades do público-alvo? De que forma preparar e mobilizar instrumentos que propiciem o desenvolvimento da competência em informação? Qual o ponto de partida para o desenvolvimento da competência em informação no ensino superior?

Os objetivos da modelagem proposta foram, então, definidos como sendo: reforçar a concepção da competência em informação no ensino superior, tendo em vista a melhoria contínua; promover a reflexão em torno das 
práticas de desenvolvimento da competência em informação; disponibilizar um conjunto de metodologias e instrumentos de apoio às práticas de aprendizagem com base no desenvolvimento da competência em informação e apoiar educadores ou entidades interessadas em desenvolver instrumentos educacionais com base no desenvolvimento da competência em informação.

\subsection{Elaboração, Representação e Descrição da Modelagem}

Optou-se por elaborar a modelagem na forma de diretrizes básicas e que se encontram descritas na Figura 1. O propósito é contribuir com a inserção dos conceitos e princípios da competência em informação nas práticas educativas dos cursos de Biblioteconomia e, em decorrência, para a área da Ciência da Informação.

Figura 1 - Modelagem Conceitual Pedagógica para o Desenvolvimento de Competência em Informação - (MPDColnfo): diretrizes básicas

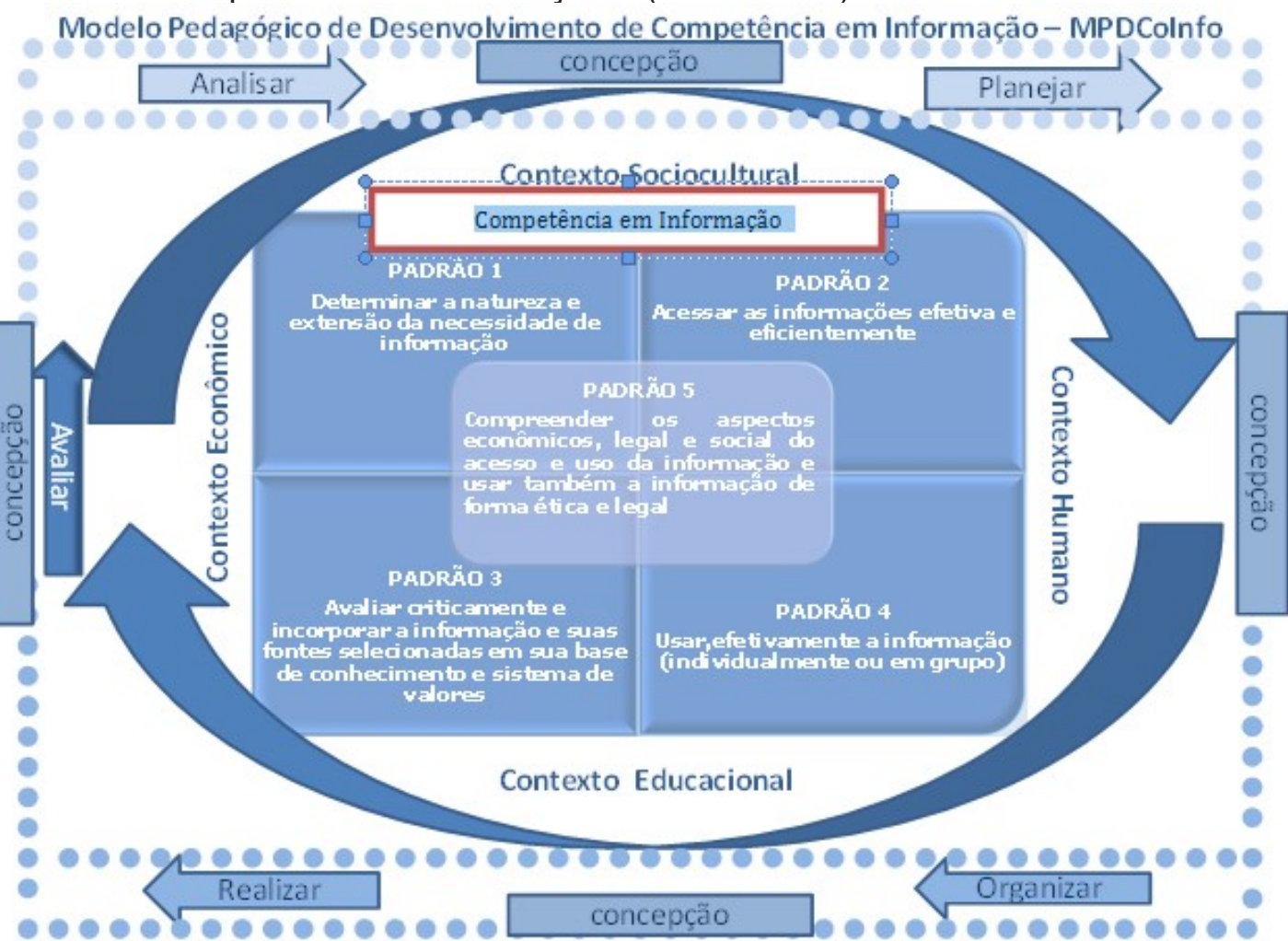

Fonte: Farias, 2014.

Pode-se descrever a modelagem conceitual proposta como sendo um conjunto estruturado de cinco fases, processos e instrumentos de apoio à concepção de programas, cursos e soluções pedagógicas baseadas no desenvolvimento da competência em informação, podendo ser explorado e Inf. Inf., Londrina, v. 22, n. 3, p. 112 -135, set../out. 2017. 
utilizado de várias formas, isto é, em razão das necessidades e disponibilidades - pelas entidades e profissionais que intervêm na formação.

O ciclo de desenvolvimento da competência em informação, conforme a figura 2 integra vários domínios de intervenção e, nesta proposta, sugere-se um conjunto de ferramentas que possibilitem uma modelagem conceitual pedagógica para o desenvolvimento da competência em informação durante a formação universitária de bibliotecários.

Figura 2 - Ciclo de desenvolvimento da competência em informação

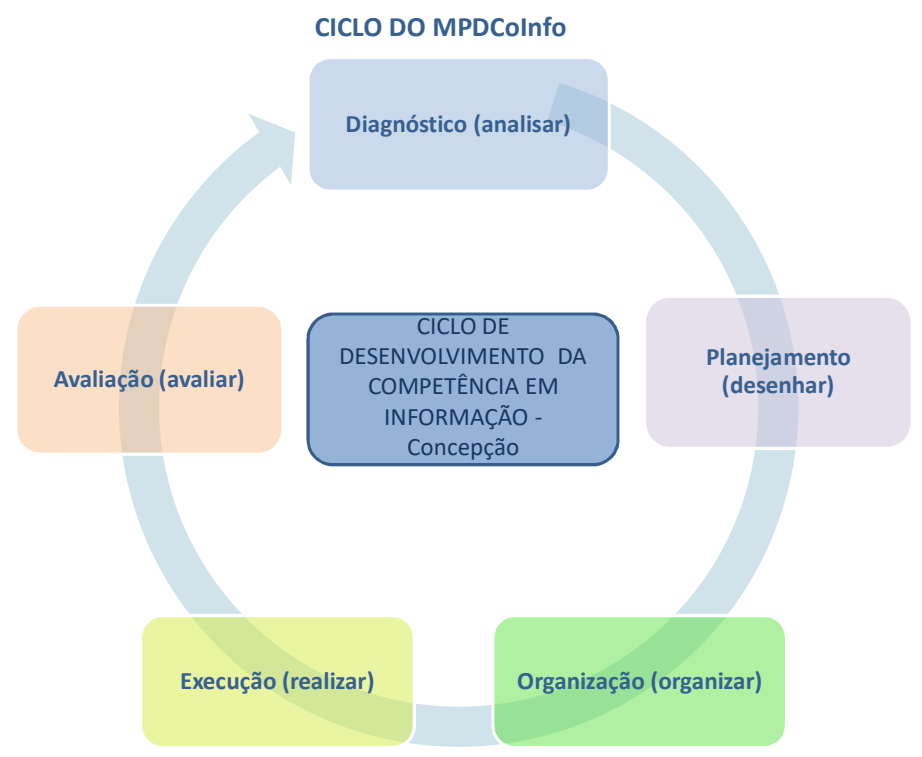

Fonte: Farias, 2014

O ciclo de desenvolvimento da competência em informação prevê cinco fases distintas, integradas e complementares, conforme está no quadro 3.

Quadro 3 - Fases do ciclo de desenvolvimento da competência em informação

\begin{tabular}{|l|l|}
\hline \multicolumn{2}{|c|}{ DESCRIÇÃO } \\
\hline Fase I - ANALISAR & $\begin{array}{l}\text { Diagnosticar os contextos de partida, ou seja, sinalizar } \\
\text { quais padrões da competência em informação serão } \\
\text { delineados e elaborados para a definição dos objetivos } \\
\text { de aprendizagem, com base no pressuposto de que os } \\
\text { objetivos consistem na tradução pedagógica das } \\
\text { competências/habilidades pré-identificadas. }\end{array}$ \\
\hline & $\begin{array}{l}\text { Planejar a proposta formativa, visando a delinear } \\
\text { itinerários de aprendizagem conforme os contextos e }\end{array}$ \\
\hline
\end{tabular}

Inf. Inf., Londrina, v. 22, n. 3, p. 112 - 135, set../out. 2017. http:www.uel.br/revistas/informacao/ 


\begin{tabular}{|l|l|}
\hline Fase II - DESENHAR & $\begin{array}{l}\text { público-alvo, sendo que a concepção do itinerário a } \\
\text { desenvolver deverá agregar os objetivos de } \\
\text { aprendizagem estabelecidos na Fase I. }\end{array}$ \\
\hline Fase III - ORGANIZAR & $\begin{array}{l}\text { Estabelecer a sequência pedagógica, partindo da } \\
\text { definição de objetivos estabelecidos na Fase I, visando } \\
\text { a contribuir para a indicação e sequência de conteúdos } \\
\text { a incorporar nas soluções formativas, assim como } \\
\text { identificar as melhores estratégias pedagógicas a } \\
\text { aplicar. }\end{array}$ \\
\hline Fase IV - REALIZAR & $\begin{array}{l}\text { Construir ou identificar recursos técnico-pedagógicos e } \\
\text { suporte de apoio à equipe de facilitadores (docentes, } \\
\text { monitores, tutores...) e também aos alunos. }\end{array}$ \\
\hline Fase V - AVALIAR & $\begin{array}{l}\text { Aferir a estratégia pedagógica, visando a elaborar a } \\
\text { estratégia avaliativa mais adequada às características } \\
\text { da teoria de aprendizagem previamente concebida. }\end{array}$ \\
\hline
\end{tabular}

Fonte: Crédito da autora, 2014.

A cada fase da MPDColnfo proposta, surgem os processos, que nada mais são senão a realização das referentes atividades recomendadas, sempre que possível em instrumentos de apoio à decisão e à sistematização do trabalho de concepção do ciclo de desenvolvimento da competência em informação, de forma a serem produzidas evidências que documentem e comprovem a coerência, a fundamentação e a robustez dos passos metodológicos desenvolvidos para a criação de uma proposta formativa de inserção da competência em informação na matriz curricular dos cursos de Biblioteconomia no Brasil como política pedagógica institucionalizada.

As atividades recomendadas em cada uma das fases do ciclo de concepção do MPDColnfo devem ser abordadas na perspectiva de quem se responsabiliza pela concepção de um projeto de formação (podendo ser a equipe pedagógica da instituição ou mesmo um docente). Ressalta-se que a responsabilidade da preparação de uma proposta formativa deverá ser ajustada às necessidades do respectivo público-alvo.

Quando da prática da modelagem conceitual proposta para o desenvolvimento da competência em informação, sugere-se a elaboração de um plano de ação considerado aqui como eventual ênfase de um processo de concepção do ciclo de desenvolvimento dessa competência. 


\section{CONSIDERAÇÕES FINAIS}

É necessário ressaltar que um dos primeiros passos para a mediação numa concepção de construção do conhecimento é questionar e redefinir os papéis dos sujeitos na educação, para que o docente, enquanto mediador desse processo possa analisar sua práxis pedagógica, construindo novas possibilidades de aprendizagem.

Os docentes são autores e atores fundamentais à mudança educacional que buscam, portanto, é necessário que possam ter múltiplos papéis e funções, não só com a informação científica precisa e atualizada, mas, também, com todas as competências estruturantes do pensamento e da ação que intentam desenvolver nos seus próprios alunos. Este é um dos grandes desafios hoje, enquanto formadores. Para isso, é preciso selecionar estratégias pedagógicas que possibilitem o desenvolvimento de competência em informação.

Verifica-se, além disso, que é necessário que o docente ao apropriar-se do conceito de competência em informação e colocá-lo em prática por meio de intervenções pedagógicas, tem condições de influenciar positivamente na aprendizagem, pois amplia o grau dessa competência nos alunos. Essas intervenções colaboram para que eles possam atuar efetivamente nessa sociedade. Dessa forma, eles precisam participar de um programa de competência em informação desde as séries iniciais.

Um programa de competência em informação envolve aspectos de mudança de filosofia nas universidades, de modo a internalizar políticas e diretrizes com tal filosofia à proposta curricular. Esperamos que este trabalho represente uma pequena semente e incentive os docentes, especialmente do Curso de Biblioteconomia, a realizar e experimentar ações pedagógicas, tendo como base o desenvolvimento de competência em informação.

A formação do bibliotecário não está somente focada nos conhecimentos técnicos e teóricos, pois isso não garante a produtividade e a efetividade de sua atuação no mercado de trabalho; é necessário impulsionar mudanças significativas na sua formação, para que estes profissionais assimilem e adotem atitudes que venham intervir na sociedade. Essa formação 
precisa ser efetivamente crítica e reflexiva, contribuindo para que o bibliotecário possa reavaliar permanentemente sua atuação buscando direcioná-la rumo aos princípios de humanização e emancipação da sociedade e do individuo.

\section{REFERÊNCIAS}

AMERICAN LIBRARY ASSOCIATION - ALA. Presidential Committe on Information Literacy: final report. (1989) Disponível em: $<$ http://www.ala.org/ala/acrl/acrlpubs/whitepapers/presidential.htm>. Acesso em: 03 set.2013.

ASSOCIATION OF COLLEGE AND RESEARCH LIBRARIES - ACRL. Information literacy competency for higher education. Chicago: ALA, 2000. Disponível em:

$<$ http://www.ala.org/ala/mgrps/divs/acrl/standards/informationliteracycompetenc ystan dards.cfm>. Acesso em: 06 ago. 2013.

BADKE, W. Why information literacy is invisible. Communications in Information Literacy, v.4, n.2, 2010, p.129-141.

BELLUZZO, R. C. B. Competência em informação: vivências e aprendizado. In: Regina Celia Baptista Belluzzo; Glória Georges Feres. (Org.). Competência em informação: das reflexões às lições aprendidas. São Paulo: FEBAB, 2013, v. 1 , p. $58-74$.

.Construção de mapas: desenvolvendo competências em informação e comunicação. 2. ed. Bauru: Cá entre Nós, 2007. v. 1. 111p .

O uso de mapas conceituais para o desenvolvimento da competência em informação. In: PASSOS, R.; SANTOS, G. C. (Org.). Competência em informação na sociedade da aprendizagem. Bauru: Kayrós, 2005b. p.29-49.

BRASIL. Leis e Decretos. Lei n ${ }^{\circ}$.394, de 20 de dezembro de 1996. Estabelece as diretrizes e bases da educação nacional. Brasília, DO 23/12/1996.

BRASIL. Ministério da Educação. Diretrizes Curriculares Nacionais dos cursos de Filosofia, História, Geografia, Serviço Social, Comunicação Social, Ciências Sociais, Letras, Biblioteconomia, Arquivologia e Museologia, 2001. Disponível em: $<$ http://portal.mec.gov.br/cne/arquivos/pdf/CES0492.pdf>. Acesso em: 12 set. 2012

BRUCE, C. S. Information literacy research: dimensions of the emerging collective consciouness. AustralianAcademic\&ResearchLibraries, v.31, n.2, p. 91-106, 2002. 
CAMPELO, B. O movimento da competência informacional: uma perspectiva para o letramento informacional. Ciência da Informação, Brasília, v.32, n.3, p.28-37, set/dez. 2003.

CAVALCANTE, L. E. Políticas de formação para a competência informacional: o papel das universidades. Revista Brasileira de

Biblioteconomia e Documentação: Nova Série, São Paulo, v. 2, n. 2, p. 4762, dez. 2006.

CHAUI, M. A universidade publica sob nova perspectiva. Revista Brasileira de Educação, n.24,p.5-11, set.-dez./2003.

CERVERÓ CUEVAS, A. Alfabetização em informação e educação a distancia: uma relação necesaria. In.: LINHARES, R. N.; LUCENA,S.; VERSUTIA A. As redes sociais e seu impacto na cultura e na educação do século XXI. Fortaleza: Edições UFC, 2012. p.85-148

COONAN, E. A new curriculum for information literacy. Theoretical background - Teaching learning: perceptions of information literacy. Arcadia Project, Cambridge University Library. 2011.

DELORS, J. (Org). Educação: um tesouro a descobrir. São Paulo: Cortez/Brasília: MEC: UNESCO, 1998.

DOYLE, C. S. Information literacy in information society: a concept for the information age. New York: Syracuse University, 1994.

DUDZIAK, E. A. InformationLiteracy e o papel educacional das bibliotecas e do bibliotecário na construção da competência em informação.. In: ENDOCOM. Encontro da Rede Nacional de Centros de Informação e Bibliotecas da Área de Comunicação Social, 12., , 2002b, Salvador. ENDOCOM 2002: anais.. São Paulo: Intercom, 2002.

FARIAS, G. B. O Bibliotecário - gestor da informação:representações do segmento imobiliário sobre competências. 2007. Dissertação (Mestrado em Ciência da Informação) - UFSC, Florianópolis/SC, 2007.

Competência em informação no ensino de biblioteconomia: por uma aprendizagem significativa e criativa . $183 \mathrm{f}$. Tese (Doutorado em Ciência da Informação ) - Faculdade de Filosofia e Ciências, Universidade Estadual Paulista. Marília: UNESP, 2014.

GASQUE, K. C. G. D. Arcabouço conceitual do letramento informacional. Ci. Inf., Brasília, DF, v. 39 n. 3, p.83-92, set./dez., 2010.

LAU, J. Diretrizes sobre desenvolvimento de habilidades em informação para a aprendizagem permanente. 2007. Disponível em:

<http://www.febab.org.br/jesus lau trad livro comp v f.doc>. Acesso em: 14 nov. 2008. 
MATA, M. L.; CASARIN, H. C. S. Inserção de conteúdos de competência informacional e de formação pedagógica nos currículos dos cursos de Biblioteconomia do Brasil: uma análise por meio dos sites institucionais. In: Encontro Nacional de pesquisa em Ciência da Informação - ENANCIB, 2012, Rio de janeiro. Anais do XIII Encontro Nacional de pesquisa em Ciência da Informação - ENANCIB. Rio de Janeiro: Fiocruz, 2012. p. 1-21.

PIANTOLA, D. ; VITORINO, E. V. Dimensões da Competência Informacional. Revista Ciência da Informação (Impresso), v. 40, p. 99-110, 2011.

SANTOS, A. S. Fundamentos da teoria histórico-cultural para a competência em informação no contexto escolar. 2013. 86f. Dissertação (Mestrado em Ciência da Informação) - UNESP, Marília, 2013.

STUBBINGS, R.; FRANKLIN G. 'Does advocacy help to embed information literacy into the curriculum? A case study' Italics, n. 5, v.1, 2006. Disponível em:<http://www.ics.heacademy.ac.uk/italics/vol5iss1.htm>. Acesso em: 8 Jul. 2011.

TAKAHASHI, T. Sociedade da Informação no Brasil: livro verde. Brasília: Ministério da Ciência e da Tecnologia, 2000.

UNESCO. Política de mudança e desenvolvimento no Ensino Superior. Rio de Janeiro: Garamond/Unesco, 1998.

URIBE-TIRADO, A.. La Alfabetización Informacional en la Universidad.

Descripción y Categorización según los Niveles de Integración de ALFIN. Caso Universidad de Antioquia. Revista Internamericana de Bibliotecología, v.33, n.1, 2010, p.31-83. Disponível em: $<$ https://aprendeenlinea.udea.edu.co/revistas/index.php/RIB/article/view/6280>. Acesso em: 8 Jul. 2011.

VARELA, A. V.; BARBOSA, M. L. A. ; FARIAS, M. G. G. Desenvolvimento de competências informacionais, científicas e tecnológicas: responsabilidade do ensino superior com parceria entre a docência e a biblioteca. In: BELLUZZO, R. C. B.; Feres ,G. G. (Org.). Competência em informação: das reflexões às lições aprendidas. São Paulo: FEBAB, 2013, v. 1, p. 176-208.

Title

Information literacy: perspective educational teaching

\begin{abstract}
:
Introduction: It presents reflection on the teaching-learning actions that can positively influence the formation of Librarianship course students in the Brazilian context, to take ownership of the "Pedagogical modeling Competence Development in Information" by putting it into practice through educational interventions . Objective: The aim was to prepare the above model based on the rules of The Association of College and
\end{abstract}


Research Libraries who believe that information literacy is common to all disciplines, to all learning environments and to all levels of education. Methodology: The research sets up a qualitative approach to literature and exploratory nature. Results: Pedagogical modeling Competence Development in Information Conclusions: This is a contribution of innovative and social aspects interested in adopting new postures in this teaching-learning ambience, as well as assist in the understanding of the fundamental issues related to information literacy, allowing its appropriation from the Library courses and promoting the depth reflections sometimes pointed and the need to implement it as part of the basic training of the librarian.

Keywords: Information Literacy. Professional Qualification. Librarianship. Teaching.

\section{Titulo}

Competencia en información: perspectiva didáctica pedagógica

Introducción: Se presenta reflexión sobre las acciones de enseñanza aprendizaje que pueden influenciar positivamente en la formación de los discentes del curso de Biblioteconomía en el contexto brasileño, al apropiarse del "Modelamiento Pedagógico de Desarrollo de la Competencia en Información", poniéndola en práctica por medio de intervenciones pedagógicas. Objetivo: El objetivo fue elaborar el modelo antes citado teniendo como base la normativa de la Asociación de Colegios y Biblioteca de la Biblioteca que consideran que la competencia en información es común a todas las disciplinas, a todos los contextos de aprendizaje ya todos los niveles de enseñanza. Metodología: La investigación se configura por un enfoque cualitativo de naturaleza bibliográfica y exploratoria. Resultados: Modelamiento Pedagógico de Desarrollo de la Competencia en Información. Conclusiones: Se trata de una contribución de aspecto innovador y social a los interesados en la adopción de nuevas posturas en este ambiente de enseñanza-aprendizaje, además de auxiliar en la comprensión de las cuestiones fundamentales relacionadas con la competencia en información, posibilitando su apropiación junto a los cursos de Biblioteconomía y promoviendo La profundización de las reflexiones ya señaladas y la necesidad de implementarla como parte de la formación básica del bibliotecario.

Palabras clave: Competencia en Información. Formación profesional. Biblioteconomía. Enseñanza.

Recebido em: 03.08.2016

Aceito em: 13.12.2017 